\title{
El dirigismo de la información $y$ el dominio del miedo
}

Information "dirigism" and the domain of fear

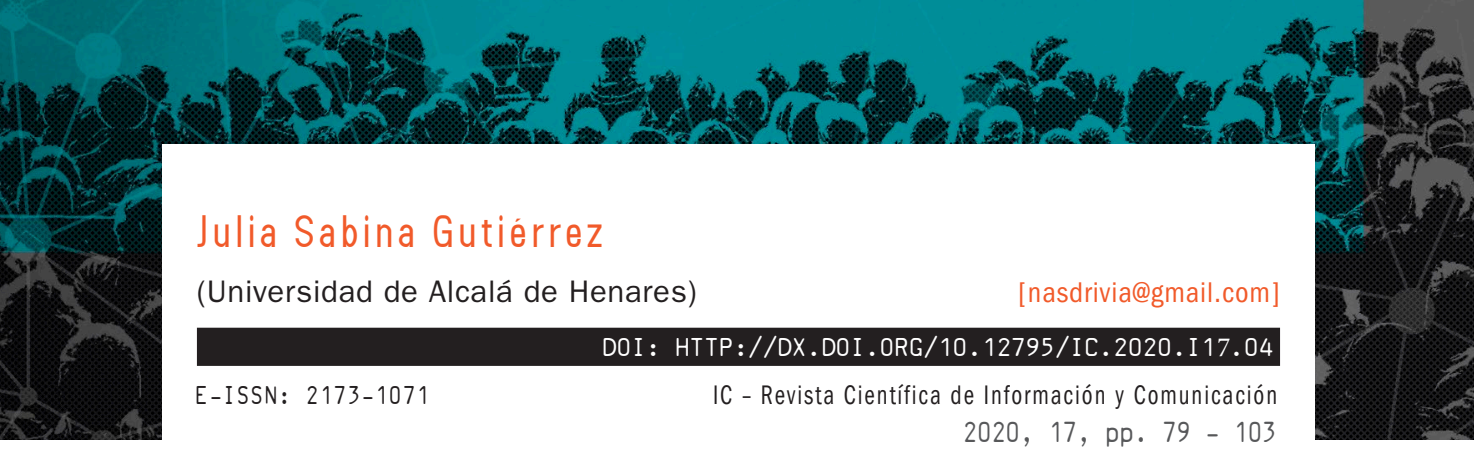

2020, 17, pp. $79-103$

\section{Resumen}

Las grandes potencias siempre han intentado dirigir los medios de comunicación, que constituyen el mejor instrumento de la democracia para intentar eliminar las desigualdades. En esta tarea, casi siempre los Estados Unidos han gozado de la hegemonía, pero en los últimos tiempos están surgiendo serios y potentes competidores. Para mantener ese papel de liderazgo, Donald Trump trata de controlar e incluso de cerrar los medios, imponiendo la política del miedo.

\section{Abstract}

Great powers have always tried to control the media, the best instrument of democracy to try to eliminate inequalities. In this task, the United States has almost always enjoyed hegemony, but in recent times serious and powerful competitors have emerged. To maintain that leading role, Donald Trump tries to control and even shut down the media, imposing the politics of fear.

\section{Palabras clave}

Comunicación, Imperialismo, Verdad, Miedo.

\section{Keywords}

Communication, Imperialism, True, Fear 


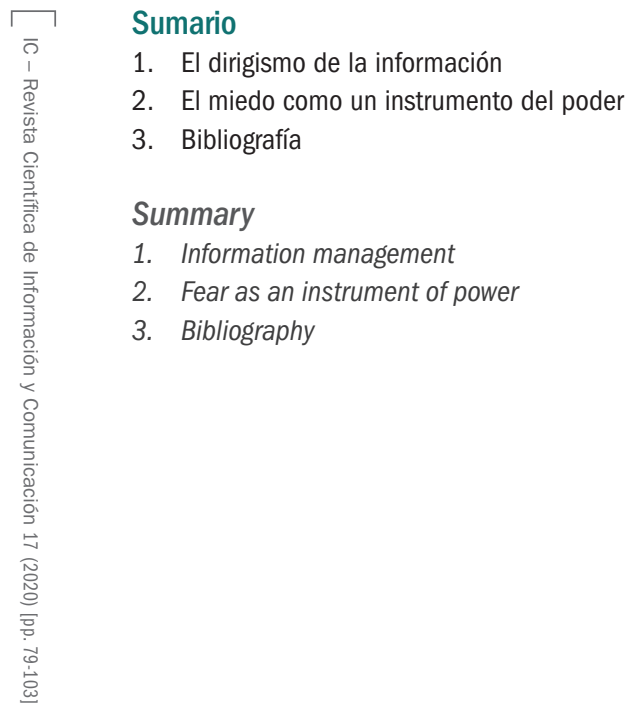

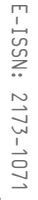




\section{El dirigismo de la información}

El historiador y periodista Paul Preston ha comparado los tuits de Donald Trump con las notas matinales de Primo de Rivera, por el intento en ambos casos de dirigir, controlar y manipular la información. El general Miguel Primo de Rivera, aunque no menos dictador, parecía más diestro en el manejo de la pluma que el mandatario norteamericano, definiendo en una de esas notas a Valle-Inclán como "eximio escritor y extravagante ciudadano". Durante su Dictadura, que comprende desde 1923 al 1930, ejercida bajo el reinado de Alfonso XIII, colabora frecuentemente en la prensa y crea sus propios órganos de opinión para defender e intentar blindar su política absolutista. Uno de estos medios fue el periódico La Nación, fundado a instancias del propio general y financiado en una gran parte con los presupuestos de la Administración. Le ofreció la dirección del periódico al escritor José Martínez Ruiz “Azorín”, que había publicado ya en esas fechas algunas de sus principales obras. Pero el autor de La voluntad rechazó la oferta, y el Dictador le encargó entonces la dirección a un teniente coronel de su confianza. Todo quedaba en el campo de la milicia, aunque pronto el militar fue sustituido por el periodista Manuel Delgado Barreto, que había coordinado el diario La Acción, inspirado en la ideología de Antonio Maura, y desde el que había alentado los principios de la dictadura primorriverista. En La Nación insertaron diversos artículos escritores como José María Pemán, José Calvo Sotelo, César González Ruano, y de manera especial Ramiro de Maeztu, que tuvo que dejar su colaboración en periódico El Sol, para incorporarse al otro diario.

La tentación de dirigir y manipular a los ciudadanos es muy frecuente en los gobernantes, llegando en ocasiones una misma persona a ostentar el poder ejecutivo y el control de los principales medios de comunicación, como fue el caso del periodista deportivo Silvio Berlusconi.

En esta línea, los mensajes de Trump son cada día más intimidatorios, amenazando con regular fuertemente las redes sociales e incluso con llegar a clausurarlas. Estos avisos se suman a los lanzados contra las movilizaciones por la muerte de George Floyd, asfixiado por la policía, y a los enviados a los propios gobernadores acusándolos de débiles y de "imbéciles si no hay arrestos". En otro tuit advierte que, si los gobernadores se niegan a actuar, "desplegará al Ejército de Estados Unidos y rápidamente resolverá el problema por ellos".

El mandatario estadounidense se ve casi incapaz de gobernar su propio territorio, pero no renuncia a su papel de sheriff global, aunque cada día le surjan nuevos competidores. Con una sofisticación de las medidas imperialistas, recurre incluso a los 
nuevos avances de la inteligencia artificial para la manipulación de los ciudadanos, como ha intentado hacer con las investigaciones del neurólogo español Rafael Yuste. Este profesor de la universidad de Columbia, apoyado por otros científicos, presentó al presidente Obama un proyecto para estudiar el cerebro, en febrero del año 2013, que fue dotado con 100 millones de dólares. El objetivo del proyecto era componer el mapa íntegro de toda la actividad neuronal en la web compartiéndolo con los trabajos de otros neurólogos y científicos. La visualización de la actividad intrínseca del cerebro puede tener muchas aplicaciones, como mejorar la actividad mental o leer y controlar los pensamientos de la gente. Esto último es lo que intenta llevar a cabo la administración Trump. Sobre la manipulación y la utilización torticera de la información se pronunció Noam Abram Chomsky, cuando descubrió que sus investigaciones estaban siendo aprovechadas en la guerra de Vietnam. Renunció a la subvención y fue entonces relegado a un sótano en el Instituto de Tecnología de Massachussets, de donde se ha traslado hace unos meses a un lugar menos frío. A pesar de estas medidas, Chomsky (2010), Kaldor (2010) y otros investigadores han seguido criticando las nuevas formas de imperialismo norteamericano. Noam Abram Chomsky, como observa Darío Villanueva, vuelve a advertir sobre la utilización de "Ios medios de comunicación para 'crear consensos', para producir en la población, mediante una verdadera ingeniería propagandística, la aceptación mayoritaria de algo no deseado en principio, para “domesticar el rebaño desconcertado" (Villanueva, 2019, 56).

Malcolm Gladwell, a su vez, nos avisa de la debilidad fatal que tenemos ante los despostas, sobre todo cuando les imprimen a sus discursos, aunque sean falsos, "un sesgo de veracidad" (Glawell, 2020). Cada día se suman más intelectuales y escritores a esta protesta contra la política represiva de Trump y el intento de manipular los medios.

El peligro surge cuando desde las redes del Poder se intenta "dominar las redes neuronales de los cerebros humanos" (Castells, 2009). Sobre ese peligro también han advertido los neurólogos que fundaron el Proyecto Genoma Humano, que "organizó un consorcio inicial de veinte universidades de seis países (Estados Unidos, Reino Unido, Japón, Francia, Alemania y China" al que se fueron uniendo otros grupos de investigación de todas las naciones desarrolladas" (Alonso \& Alonso Esquisábel, 2018, 132). Si "los resultados obtenidos fue el conocimiento de que los seres humanos poseían unos veinte mil genes, un número similar al del ratón y mucho menor de lo que se esperaba" (Alonso, Alonso Esquisábel, 2018, 134), y los ratones son los modelos que se utilizan para luego aplicar a los humanos, el control de estos, aunque sea reprobable, no resulta difícil.

En este sentido, la inteligencia artificial -el algoritmo, el Big Data, machine learning- permite el empleo del neuromarketing y remote sensing a escala no conocida 
hasta ahora en la manipulación de las preferencias y las decisiones de la persona sobre datos extraídos a terceros, que ni tan siquiera sabe de su existencia, sea con el fin de beneficio o de control e influencia. En el campo político Donald Trump recurrió ya en las elecciones del 2016 a Cambridge Analytica para dirigir el comportamiento de los votantes, y está utilizando los instrumentos de esta y de otras compañías de cara a las elecciones de noviembre de 2020.

Nunca un movimiento político internacional tan radical tuvo la precisión y el poder de este tipo de tecnología propagandística para moldear los aspectos fundamentales de la política mundial en el futuro. Las elecciones de 2020, además de la lucha de ideas, serán una auténtica batalla por el control automatizado del comportamiento de los ciudadanos.

Con esta y con otras lamentables excepciones, la inteligencia artificial es un instrumento y un aliado poderoso para lograr el bien del individuo, de la investigación y de la sociedad. Está colaborando, así -en esta época de la denominada por algunos de posverdad- a desvelar la mentira, que es en definitiva lo que significa ese término. Con la ayuda de ese instrumento, el diario The Washington Post, del 20 de enero del 2020, reveló que el presidente Donald Trump dice un promedio de 23 mentiras o declaraciones engañosas al día.

En esta línea, numerosas empresas internacionales han dejado de anunciarse en las compañías de Mark Zuckerberg, hasta que se implique más en la moderación de contenidos y elimine los mensajes que incitan al odio o difunden informaciones falsas en sus plataformas. Mark Zuckerberg mostró su apoyo a Trump, tras las protestas de sus propios empleados.

Los informadores de Trump manipulan el lenguaje, rehúsan, por ejemplo, el término "administración" y prefieren el de "gobernanza”, con el que incorporan también a los actores privados en sus prácticas políticas.

Estados Unidos reaviva la guerra fría, ahora contra China, que sustituye a una Rusia despojada de parte de su territorio, de su poder y hasta del nombre. Mike Pompeo, el Secretario de Estado norteamericano, ha declarado que el partido comunista chino es más peligroso que terrorismo internacional. Muchos países están tratando de evitar las presiones de ambas superpotencias y mantenerse neutrales, aunque la Unión Europea, ante las medidas proteccionistas de Trump, ha comenzado a aplicar aranceles a algunos productos estadounidenses. La mayoría de los dirigentes europeos confía, sin embargo, en restablecer la armonía transatlántica cuando haya un relevo en la Casa Blanca, tal vez incluso el próximo mes de noviembre. Aunque esto suponga un alivio, la actitud dirigista de los presidentes estadounidenses ha ocupado siempre espacios de las publicaciones 
internacionales y ha merecido la atención de prestigiosos investigadores como Robertson (1992), Giddens (1993, 1998), Albrow (1996), Beck (1998), Boron (2002), Bauman (2003), Palomares (2006) Joseph Stiglitz (2007), Fernández (2010). Del Arenal (2010), Rodrik, (2011), Barberá de la Torre (2012), Milanovic (2016), Gladwell (2020)...

Para Atilio Boron, la administración de Busch hijo, sobre todo a partir de los viles crímenes de septiembre de 2001, limitó de forma radical el papel de intervención de sus aliados, aunque acudía a los mismos, cuando así lo dictaminaban sus propios intereses (Boron, 2002). Los gobiernos de otros países, presididos por políticos de carácter conservador, se sentían cómodos desempeñando este papel de invitados.

Se creó, así, una nueva articulación y relación entre el poder norteamericano y los de los gobiernos occidentales, aumentando las desigualdades, tanto en los dominios del imperio como en el seno de los territorios de sus socios (Bauman, 2003). A la vez surge una nueva dialéctica entre las posturas localistas y globalizadoras (Harvey, 2007, Robinson, 2007).

Como comentan algunos analistas, el imperialismo se impone especialmente "cuando se hace necesario organizar su influencia contra los poderes recalcitrantes -los estados parias en su jerga-, o dicho de otra manera, contra zonas o grupos que no aceptan la orden impuesta por Washington. Entonces el sheriff reúne a un destacamento de estados voluntarios para que le ayuden a restablecer el orden" (Schiller $(2002,119)$. Frente a esta postura, Joseph Stiglitz llega incluso a defender "la desconexión parcial de los países del comercio global, para no aumentar las desigualdades entre ricos y pobres" (Stiglitz, 2007).

Para que estas relaciones "repercutan de manera positiva en el crecimiento y desarrollo de los diversos países, serán siempre necesarios bajos niveles de corrupción, infraestructuras adecuadas y estabilidad económica y política” (Barberá de la Torre, 2012, 477). A ello contribuirá igualmente el correcto funcionamiento en libertad de los diversos medios de comunicación.

Las administraciones de George Bush padre y George Bush hijo elevaron a sus máximas cotas el poder de la información para hacer publicidad de sus propios mandatos. Como un arma más se utilizó la transmisión en directo de la Guerra del Golfo, que comenzó con estas palabras del presentador de CNN, Bernie Shaw, por el 4 WIRE: "Algo está ocurriendo afuera... Ios cielos de Bagdad han sido iluminados". También se transmitieron en directo muchos de los ataques de la guerra contra Irak, y el presidente Barack Obama y sus asesores de seguridad siguieron desde la Casa Blanca la operación del comando para acabar con Bin Laden, también transmitida por televisión. Sin embargo, no existía en Estados Unidos una Ley de Información, y esta fue promulgada en el año 
2010 por el mismo presidente Obama. La ley tomó el nombre Daniel Pearl, asesinado por grupos islamistas ocho años antes.

Dicha ley, aunque en el fondo seguía persiguiendo dirigir las conductas de los ciudadanos, intentaba desmontar la tesis de que la prensa podía percibirse como un instrumento para imponer una cultura global, "según la cual los fenómenos culturales de nuestro tiempo se desarrollan en un espacio ecuménico global de interacción e intercambio cultural permanente" (Hannerz, 1996, 107). La globalización no conseguiría la unificación ni uniformidad de los comportamientos, según Featherstone, ya que "la variedad de respuestas al proceso de globalización sugiere claramente que hay pocas posibilidades de que (surja) una cultura global unificada, en vez de culturas globales en plural" (Featherstone, 1990, 10).

Para refutar los argumentos que defienden que la globalización crea más desigualdades (Milanovic, 2016) se buscan modelos que respeten las identidades nacionales y las normas políticas internacionales (Rodrik, 2011). Se trata de una polémica que varios años antes habían suscitado Ulrich Beck (1998) y García Canclini (1999).

Independientemente de estos debates, la situación política ha producido el crash económico, aunque eufemísticamente se lo denomine crisis, y el crash político entró en plena ebullición, con las "primaveras" del mundo árabe, con la denominada spanishrevolution y ahora se incrementado con la pandemias vírica, social y económica.

En esta situación, entre los objetivos de los diversos poderes, especialmente el de la administración estadounidense, viene destacando desde hace años el de la información: "la generación de riqueza, el ejercicio del poder y la creación de códigos culturales han pasado a depender de la capacidad tecnológica de las sociedades y las personas, siendo la tecnología de la información el núcleo de esta capacidad" (Castells $(1998,114)$. Como explica el mismo Castells, "Ias divisiones sociales fundamentales de esta era de la Información son la fragmentación interna de la mano de obra entre productores informacionales y trabajadores genéricos reemplazables, la exclusión social de un segmento significativo de la sociedad compuesto por individuos desechados y la separación entre la lógica de mercado de las redes globales de los flujos de capital y la experiencia humana de las vidas de los trabajadores" (Castells, 1998, 127). Por otra parte, el teletrabajo durante la pandemia ha sido el privilegiado o el único que se ha empleado en algunas empresas, pero en la nueva reconstrucción está suponiendo la supresión de puestos de trabajo según argumentan sus representantes sindicales y las publicaciones periódicas más recientes. Según el profesor Castells "El poder como capacidad de imponer la conducta, radica en las redes de intercambio de información y 
manipulación de símbolos, que relacionan a los actores sociales, las instituciones y los movimientos culturales, a través de iconos, portavoces y amplificadores intelectuales" (Castells, 1998, 129). Este nuevo sistema de comunicación ha generado una nueva cultura: "Al recluir al poder en el espacio de los flujos, permitir al capital escapar del tiempo y disolver la historia en la cultura de lo efímero, la sociedad red desencarna las relaciones sociales, induciendo la cultura de la virtualidad real (...) En el paradigma informacional ha surgido una nueva cultura de la sustitución de los lugares por el espacio de los flujos y la aniquilación del tiempo por el tiempo atemporal: la cultura de la virtualidad real" (Castells, 1998, 131-132).

Por su parte el sociólogo italiano Mauro Wolf $(1997,244)$ ha declarado que los medios desempeñan un doble papel: "están en la esfera social, formando parte integrante de la misma, y a la vez la definen, reproduciendo y estableciendo los criterios de visibilidad y relevancia social de los fenómenos colectivos. En esta planetarización del sistema, los medios son el instrumento de internacionalización de las conductas colectivas (...). La circulación de informaciones unifica potencialmente el sistema mundial, y al mismo tiempo mundializa los problemas y los terrenos en los que nacen los conflictos. La globalización puede generar procesos de imitación de las conductas presentadas por los medios o procesos de afirmación de la propia identidad. La radicalización de este segundo proceso constituiría la otra cara de la aldea global: la proliferación de tribus fragmentadas y difusas" (Wolf, 1997, 249). En el marco de la antiglobalización, según Ella Shohat y Robert Stam, "se han construido las estéticas de la resistencia, se ha reescrito, gracias a ciertos filmes, la historia colonial, se han filmado los documentales combativos del Tercer Cine... se ha utilizado el sincretismo como estrategia artística, y frente a los discursos dominantes, se ha desplegado una especie de jiu-jitsu mediático, ejemplificado en películas como la australiana Babakiueria (1986), de Don Featherstone o la brasileña Ilha das Flores (1990) de Jorge Furtado" (Shohat-Stam, 2002, 249-315).

En el contexto de estos debates, el político y escritor canadiense Michael Ignatieff, que ha vertido opiniones muy controvertidas sobre el intervencionismo en Siria -uno de los escenarios de operaciones bélicas con distinto signo e intereses supranacionales diferentes- en su libro The Needs of Strangers, subrayaba la importancia de las relaciones internacionales (Ignatieff, 1986), pero en esta relación con los demás hay que tener en cuenta, como advierte Malcolm Gladwell en su obra Hablar con extraños, que "los desconocidos no son simples" (Gladwell, 2020).

Giovani Mannetti ha analizado este intercambio comunicativo, este diálogo con extraños o con conocidos desde la perspectiva semiótica de la comunicación: "La 
comunicación que se establece a través de los medios moviliza los 'efectos de realidad' fundamentales para instaurar la creencia y la persuasión, e introduce las imágenes o simulacros del enunciador y del enunciatario, así como el simulacro del intercambio comunicativo. El hecho de que el destinatario acepte una comunicación está íntimamente ligado a la credibilidad que el emisor consiga transmitir (...) La eficacia comunicativa no consiste tanto en la comunicación recibida cuanto más bien en la comunicación asumida, en el sentido de adhesión 'íntima y total'. Si asumir la palabra del otro implica, en cierto modo, creérsela, entonces se trata de un decir para ser creídos” (Mannetti, 1995, 80-81).

En la etapa de la posverdad, la información que transmiten algunos dirigentes no se basa en los datos de una verificación empírica ni tampoco en los intereses colectivos de la sociedad que representan sino en su propio provecho y el de sus empresas.

Como recuerda Darío Villanueva, el profesor Umberto Eco, en la inauguración oficial del curso 1994-1995 en la universidad de Bolonia, impartió su lección magistral con el título de La fuerza de lo falso, "donde demuestra cómo la falsedad (...) ha sido el motor de muchos acontecimientos de la historia, lo que impone como el primer deber de la gente de cultura el mantenerse alerta para reescribir la 'enciclopedia de cada día " (Villanueva, 2019: 55).

Movido por "la fuerza de lo falso" o convencido de que "la mentira nos hará libres" (Vallespín, 2012), el mandatario norteamericano desprecia y se retira de los escenarios en los que se plantean e intentan resolverse los intereses de los ciudadanos. Así, con una actitud que podría calificarse de negacionista e incluso de obscena, el presidente Trump hace gestos de desaparecer de las tribunas internacionales, sin abandonar su propósito de dirigismo imperialista. No parece entender que, aunque quiera manejar desde la sombra y utilizando métodos inaceptables, los individuos cada vez son más conscientes de sus derechos y ya no se someten fácilmente. También parece obviar las denominadas "cadenas mundiales del valor" e incluso despreciando lo que implica el concepto de "valor" (Rosales, 2009, 77). Su administración reconoce, sin embargo, como explica el profesor y diplomático español Gustavo Palomares, que la extraterritorialidad ha fomentado la globalización económica y comercial (Palomares, 2006).

A pesar de ello, los Estados Unidos se han retirado de la UNESCO, y su presidente ha lanzado la propuesta de retirarse de la OTAN e incluso de la Organización Mundial de la Salud (OMS). Este vacío en el escenario mundial está siendo aprovechado por China, cuyo presidente Xi Jinping, ha declarado que estaba dispuesto a retomar las banderas del libre comercio mundial. En la última cumbre de Davos, celebrada en enero de este año el presidente Xi Jinping desempeñó el papel de protagonista, defendiendo medidas, hasta 
ahora impensables en un régimen como el chino. En este foro, Donald Trump ni siquiera quiso imponer su imperialismo, obvió los asuntos trascendentes y se limitó a mofarse de todos los líderes mundiales y muy especialmente de la joven activista sueca Greta Thunberg. Esta reprochó contundentemente a la clase política su pasividad: "Miráis a la gente joven en busca de esperanza, ¿cómo os atrevéis? Habéis robado mis sueños y mi infancia con vuestras palabras vacías".

Ante este mensaje, Trump, partidario de las tesis negacionistas del cambio climático, compartió en su perfil de Twitter el discurso de la adolescente y empleó la ironía para mofarse de ella: "Parece una joven feliz aguardando con esperanza un brillante y maravilloso futuro. ¡Qué agradable verlo!”.

No parece que en este contexto haya un propósito de hacer desaparecer la desigualdad -el mayor problema, junto al hambre, en todos los aspectos de la escena mundial-, sino de buscar la hegemonía mundial, recurriendo a la cultura y a la política del miedo.

\section{El miedo como un instrumento del poder}

El miedo, como cualquier mecanismo defensivo maduro, pertenece al particular dominio neurológico y, al afectar a nuestra naturaleza de seres regidos por el logos, se convierte en discurso, está implicado en importantes procesos semióticos y reclama un tratamiento en un ámbito de la comunicación social y convivencial. Se trata de un mecanismo tan determinante y tan potente, que merece indagar en su naturaleza y en algunas de las más importantes concepciones del mismo.

La neurología y la neurociencia se imponen poco a poco a otras disciplinas como la ciencia política e incluso a la ética, cuando se trata de abordar y diagnosticar asuntos como el bien o el mal o esos sentimientos de angustia, de congoja y aflicción que nos induce el miedo. Sin querer desmontar el principio ético sobre "el bien que ha de hacerse y el mal que ha de evitarse", la neurociencia nos habla en ocasiones de males necesarios. Por ejemplo, si es imprescindible amputar un miembro menor para que el resto del organismo pueda seguir funcionando, se hace necesario recurrir a ese mal menor.

Según los neurólogos y los psiquiatras, el miedo subyace en todo tipo de neurosis y puede ser higiénico y terapéutico si no se convierte en compulsivo y obsesivo. Si se llega a esta fase, la neurosis se convierte en psicosis, es decir, la situación de conflicto con la realidad se transforma en una pérdida del sentido de la propia realidad. 
El miedo, como un mecanismo neurológico anticipatorio nos avisa de posibles peligros para salvar los obstáculos.

La cultura del miedo ha existido en mayor o en menor proporción desde los comienzos de la civilización, aunque se ha incrementado en los últimos tiempos, porque se ha comprobado que, gracias a los avances técnicos se han creado las condiciones para que vida sea mejor, pero al mismo tiempo se han construido los instrumentos más sofisticados para acabar con ella en un instante. Por otra parte, las investigaciones científicas entablan desde los laboratorios de última generación de todo el mundo una dura batalla contra la pandemia que amenaza como una de las mayores pestes de la historia. A todo ello se suma el recurso al miedo como uno de los instrumentos más poderosos de los medios de comunicación utilizados por los diversos poderes públicos para presentar las cuestiones más palpitantes de los últimos tiempos, como la crisis económica y la pandemia.

Ante estos y otros acontecimientos, los países de la órbita occidental, buscan acogerse al paraguas "protector" de la Unión Europea o de la ONU, sin mostrar la animadversión norteamericana a la Organización Mundial de la Salud (OMS).

Si desde el punto de vista neurológico miedo funciona como un mecanismo de anticipación, Thomas Hobbes, considera que una forma de vencer la inseguridad que provoca el miedo es anticiparse: "No hay más forma razonable de guardarse de la inseguridad que la anticipación; esto es, dominar por fuerza o astucia a tantos hombres como se pueda hasta el punto de no encontrar poder bastante grande que logre ponernos en peligro. Y no es esto más que lo que su propia conservación requieren y lo generalmente admitido" (Hobbes, 1983, 223).

Cono no podemos estar siempre vigilantes, a la defensiva y con la sospecha o el temor de que podamos ser invadidos por lo demás, debería ser permitido a un poder, según Hobbes, tal aumento de dominio sobre los otros hombres para preservar su conservación: "Por lo demás, los hombres no derivan placer alguno (sino antes bien, considerable pesar) de estar juntos allí donde no hay poder capaz de imponer respeto a todos (Hobbes, 1983, 224).

La necesidad de protección y el miedo conducen a un pacto por el que se le reconoce al soberano el derecho y el deber de mantener la paz y de tomar las decisiones relativas a la guerra. Sin este pacto, la situación sería una guerra de todos contra todos, el miedo continuo, el peligro y la muerte: "En tal condición no hay lugar para la industria, pues los productos de la misma son inseguros y, consecuentemente, ni cultivo de la tierra, ni navegación ni disponibilidad de las comodidades importables por mar; tampoco edificaciones cómodas, ni instrumentos para mover y remover cosas que necesitan mucha 
fuerza; ni conocimiento de la superficie de la tierra, ni cálculo del tiempo, ni artes, ni letras, ni sociedad; y, lo que es peor de todo, miedo continuo y peligro de muerte violenta; y la vida del hombre, solitaria, pobre, desagradable, brutal y corta" (Hobbes, 1966, III, 113).

$\mathrm{Si}$ "Hobbes pretende que el hombre es naturalmente intrépido y ama sólo el ataque", según Rousseau, él argumenta que, si la naturaleza nos ha "destinado a estar sanos, en estadios posteriores hemos desarrollado la enfermedad, se nos ha olvidado que los frutos son de todos y que la tierra no es de nadie, y nos hemos degenerado... El surgimiento de la propiedad creó el primer mal y la desigualdad entre los hombres. La introducción de la autoridad dio lugar a la división entre dominadores y dominados. El hombre ha nacido libre, y por todas partes se postra encadenado" (Rousseau, 1979, 10-11).

El mundo universitario, y en particular la academia de Dijon, se escandalizaba por las tesis de Rousseau: "Todo comienza por la propiedad, responsable de la desigualdad de fortunas. La sociedad civil y las leyes nacen del deseo de los ricos de legitimar y así perennizar su dominación. A partir de ese momento, la sociedad entera, con su cortejo de desigualdades sociales, de jerarquías de poder, va a imponer su orden. Los magistrados, al principio elegidos, se convierten en déspotas hereditarios, los mismos que reinan hoy día" (Huisman, 1997, 200).

Esta idea sobre la propiedad privada la reitera al comienzo de la segunda parte del Discurso: "El primer hombre a quien, cercando un terreno, se lo ocurrió decir esto es mío y halló gentes bastante simples para creerle fue el verdadero fundador de la sociedad civil. ¡Cuántos crímenes, guerras, asesinatos; cuántas miserias y horrores habría evitado al género humano aquel que hubiese gritado a sus semejantes, arrancando las estacas de la cerca o cubriendo el foso: "iGuardaos de escuchar a este impostor; estáis perdidos si olvidáis que los frutos son de todos y la tierra de nadie!»" (Rousseau, 1979). Se trata de la misma tesis que ya había expuesto Don Quijote en su discurso a los cabreros: "Dichosa edad y siglos dichosos aquellos a quien los antiguos pusieron nombre de dorados, y no porque en ellos el oro, que en esta nuestra edad de hierro tanto se estima, se alcanzase en aquella venturosa sin fatiga alguna, sino porque entonces los que en ella vivían ignoraban estas dos palabras de tuyo y mío. Eran en aquella santa edad todas las cosas comunes: a nadie le era necesario para alcanzar su ordinario sustento tomar otro trabajo que alzar la mano y alcanzarle de las robustas encinas, que liberalmente les estaban convidando con su dulce y sazonado fruto" (Cervantes, 2004, 97).

Pero ni estas utopías ni las propuestas con posterioridad han influido en los administradores de la sociedad civil para que logren acabar con las desigualdades $y$ desterrar el miedo de los ciudadanos, a los que con reiterada frecuencia se trata como a 
súbditos. Más bien al contrario, el miedo se erigido en una clave y hasta en un "arte de gobernar", y el ejercicio de la política se ha constituido en fuente de control social, aunque este pensamiento ya fue expuesto por Nicolás Maquiavelo. En El arte de la guerra (De re militari, 1521) defiende que la guerra no la libran los particulares, sino que la hace el Estado, argumentos que inspiran las explicaciones de Rousseau e incluso las tesis de Hegel. Maquiavelo pone como modelo las costumbres, la estrategia y la táctica militares de los romanos, de los que exacta la disciplina y la virtud. Con una entonación, que retomará Rousseau, exclama: “Mis queridos romanos" (Maquiavelo, 1988).

El tratado de Maquiavelo cuenta con antecedentes muy antiguos y notables. No hace mucho tiempo fue recuperado El arte de la guerra, atribuido a un militar chino de alto rango llamado Sun Tzu, y que data del siglo V antes de Cristo. A pesar del título, no es un libro estrictamente de carácter bélico, aunque, según algunos politólogos influyó en la estrategia militar de Napoleón, en la política de gobernar de Mao Tse Tung y en la de otros notorios dirigentes. Es un libro de cabecera de altos ejecutivos de grandes empresas multinacionales, de destacados políticos y de aquellos que manejan los mercados financieros. Las máximas milenarias expuestas por Sun Tzu parecen tener un carácter permanente, aunque cobran una especial importancia en nuestros días, en un escenario mundial sembrado de muertes por las guerras libradas en los distintos continentes. Algunas de ellas aparecen diariamente testimoniadas por los diversos medios y otras se solapan y silencian, como las guerras sucias, argumentado razones de seguridad de los Estados. El libro de Sun Tzu, en el que se privilegia la razón ética sobre las tramas militares, aconseja una estrategia para "aplicar con sabiduría el conocimiento de la naturaleza humana en los momentos de confrontación" (Tzu, 1999). Los más poderosos mandatarios actuales solo saben o solo prefieren emplear la primera de los dos grandes máximas o bases, sobre las que se sustenta del libro e ignoran o desprecian la segunda: $1^{\text {a }}$ ) "Todo el Arte de la Guerra se basa en el engaño. $2^{a}$ ). El supremo Arte de la Guerra es someter al enemigo sin luchar" (Tzu, 1999).

El Presidente de Corea del Norte, Kim Jong-un constituye un modelo en el arte del engaño o de ocultar la verdad de varias muertes, entre ellas la de su hermano paterno Kim Jong-nam en Malasia. Las primeras noticias sobre el asesinato las proporcionaron las televisiones de Corea del Sur, y hubo una negativa rotunda a que se le realizase cualquier análisis o prueba forense por parte de los diplomáticos y funcionarios de Corea del Norte residentes en Malasia, según declararon las fuentes del Gobierno de ese país.

La segunda máxima de Sun Tzu la incumple constantemente el líder supremo de Corea del Norte, que encuentra enemigos en los escenarios más lejanos y en los 
círculos más próximos, que no solo los somete sin luchar, sino que acaba con ellos, en el momento en el que encuentra un viso de sospecha. El caso más flagrante, y comunicado por muy pocos medios, fue el asesinato que perpetró contra un tío suyo, que durante bastante tiempo había sido su consejero y asesor más cercano. Cuando empieza a sentir desconfianza y recelo, ordena que su asesor y todo su equipo sean conducidos a un patio, en el que varios perros, a los que se les había privado de comida durante muchos días, los esperaban para acabar con ellos de la forma más inimaginable.

Los gobiernos chinos vienen manifestándose como especialistas en el incumplimiento de las máximas de su mítico compatriota Sun Tzu. El seguidor de sus consignas, según algunos críticos, Mao Tse Tung, fue realmente un estratega militar, sobre todo en la guerra contra Corea, pero incumplió la norma de "someter al enemigo sin luchar". Desde el año 1958, cuando Mao declara "el gran salto adelante" hasta el año 1961, se contabilizan millones de muertos, muchos de ellos debidos a la gran hambre. A mediados del año 1959 se utilizan contra las zonas rurales estrategias que no pueden ocultar su trasfondo bélico, y fueron encarcelados diez mil campesinos. No son estas las únicas actuaciones dirigidas o promovidas por Mao Tse Tung, que desmontan los argumentos de que fuera un seguidor de las teorías de Sun Tzu.

Un caso conocido internacionalmente por el prestigio internacional de la víctima fue el del escritor y periodista Liu Xiaobo, muy crítico con el régimen de su país, que sufrió varios encarcelamientos y no pudo asistir a recibir el galardón del prestigioso Premio Nobel de la Paz, que le había sido concedido en el año 2010.

En fechas más recientes, concretamente en noviembre del año 2018 una periodista y escritora china fue condenada a diez años de cárcel por haber publicado en libro que contenía escenas de carácter homosexual, incumpliendo las leyes del propio gobierno chinos que había dictado en el año 1997 un decreto en el que no se consideraba un delito la homosexualidad. Tampoco se tuvo en cuenta otra disposición del gobierno chino del año 2001, que había dejado de considerar la homosexualidad un "desorden mental".

Silenciar e incluso acabar con los medios de comunicación es una práctica también bastante frecuente en Rusia, Estados Unidos y en otros países. Se impone la política del miedo con la encarcelación e incluso con la muerte.

En la larga relación de periodistas rusos encarcelados o muertos en circunstancias sin aclarar destaca el asesinato de Anna Politkovskaya en el ascensor del bloque de su piso de Moscú perpetrado en octubre de 2006. Esta periodista de investigación había publicado varios artículos en los que realizaba una abierta crítica contra la violación de los derechos 
humanos en Chechenia. Esta actuación tomada contra la prestigiosa periodista provocó que los medios de comunicación se impusieran una severa autocensura.

En este mismo mes de julio la periodista Svetlana Prokopyeva ha sido acusada de justificar el terrorismo en una entrevista radiofónica y se solicita para ella siete años de prisión.

Los profesionales de la información, los intelectuales y los artistas denuncian esta política de censura y de represión contra los medios de comunicación y contra los que se manifiestan pacíficamente en las calles.

En esta línea, el director ruso de cine Alexandr Sokúrov, que obtuvo por su película inspirada en el mito de Fausto, el León de Oro en el Festival de Venecia de 2011, en un acto oficial en el mismo palacio del Kremlin celebrado en diciembre de 2019, expuso al presidente Vladimir Putin su enérgica protesta por la represión contra los manifestantes opositores a la política oficial y por el encarcelamiento de numerosos jóvenes: "Nuestros jóvenes nunca vandalizan, no rompen ni destruyen nada. No queman tiendas, por ahora destacan por su conocida delicadeza. Se preocupan por su patria y nada más. En realidad, no tienen ningún otro interés que no sea el interés de su país. Y, por supuesto, hay que poner fin a esa forma represiva de relacionarse con la juventud".

Los jóvenes que se manifiestan en la plaza Roja de Moscú no son terroristas; sí lo eran los que tomaron una escuela de Beslán en septiembre del 2004, produciendo explosiones en el interior del centro. Después de unas tensas e infructuosas negociaciones, se originó un terrible tiroteo entre las fuerzas de seguridad rusas y los secuestradores armados, con el resultado de trescientos treinta y cuatro muertos y más de setecientos heridos.

Los máximos dirigentes de Estados Unidos no tienen tampoco ningún reparo en provocar el miedo, recurriendo a medios muy diversos, entre ellos, las detenciones, los encarcelamientos y los asesinatos. Con el pretexto del terrorismo islamista, a raíz de los ataques terrorista de septiembre del año 2013, el gobierno estadounidense convirtió a Guantánamo en una de las cárceles más terribles.

Nada más comenzar su mandato, el presidente Donald Trump, en el programa "60 minutos de la cadena estadounidense CBS", realizó la siguiente declaración a la periodista Lesley Stahl: "Lo que vamos a hacer es atrapar a las personas que son criminales y tienen antecedentes criminales, miembros de pandillas, traficantes de drogas, que son muchas personas, probablemente 2 millones, quizá hasta 3 millones, y los vamos a sacar del país o quizá los vamos a encarcelar". El mandatario lleva tres años cumpliendo estas promesas, está expulsando y encarcelando a inmigrantes, está construyendo el muro en la frontera con México y está practicando una dura represión con los que se manifiestan 
en contra de su régimen. En respuesta a algunos medios que han calificado sus tuits de engañosos, Donald Trump ha amenazado con "regular fuertemente o cerrar plataformas de redes sociales".

En España, después de la interminable dictadura franquista, tremendamente diestra en defender y ejercer la política del miedo, y en negar el ejercicio de la libertad, en algunos momentos de esta "etapa democrática" se ha obviado e incluso negado el discurso de la verdad. Por ejemplo, tras los ataques terroristas en las cercanías de Madrid el 11 de marzo de 2013, el gobierno de José María Aznar utilizó informaciones torticeras, atribuyendo la autoría de los atentados a la organización terrorista ETA. Sobre las diez de la mañana, Arnaldo Otegui, líder de Herri Batasuna y actualmente diputado del Congreso de España, realiza unas declaraciones condenatorias del atentado y afirma rotundamente que ETA no ha tenido ninguna intervención en los ataques. A pesar de ello, y de que no existen indicios de certeza sobre la autoría, tras la reunión del gabinete de crisis a las 13:00 horas, el gobierno comunica oficialmente que tiene la "certeza absoluta de que es ETA". Así se lo comunica la tarde de ese mismo por teléfono el presidente Aznar a los directores de los diversos periódicos de ámbito nacional, para que transmitan la noticia.

Por si esta falta a la verdad les parece insuficiente, el ministro de Interior y otros miembros del Ejecutivo, incluido su presidente, califican de "miserables" a los que ponen en duda la versión oficial.

Las máximas instancias judiciales confirmarían más tarde la falsedad de las declaraciones del gobierno de José María Aznar, probando que los atentados habían sido realizados por "una célula terrorista de tipo yihadista".

El ocultamiento de la verdad y la táctica del miedo son instrumentos también de los poderes religiosos. El fanatismo de los grupos radicales islamistas de nuestros días inspiró ya la conducta de una turba de cristianos de los siglos IV y V de nuestra era, que acabó con la vida de la matemática y filósofa Hipatia de Alejandría, cuando estaba a punto de cumplir los sesenta años. Sócrates Escolástico, contemporáneo de Hipatia, describe su asesinato de esta forma tan gráfica: "Vigilándola mientras regresaba a casa en su carro, la bajaron de él, la arrastraron y se la llevaron a la iglesia llamada Cesáreo, donde la desnudaron completamente y la asesinaron golpeándola o cortándola con tejas o conchas. Después de despedazarla, se llevaron sus miembros destrozados a un lugar llamado Cinarón y los quemaron".

En la historia de los máximos dirigentes de los católicos, hay una buena nómina de pontífices nada admirables por ordenar el encarcelamiento, el destierro y la muerte. Baste nombrar a Alejandro VI, que ordenó matar a los cardenales que le hacían sombra o 
a Bonifacio VIII, al que Dante Alighieri, a quien el papa había desterrado, lo colocó en el octavo círculo del "inferno" de su Divina Commedia.

En tiempos más cercanos, el papa Pío XII ha sido criticado por su silencio ante los crímenes nazis e incluso se lo ha considerado como el "Papa ideal para el indecible plan de Hitler" (Cornwell, 2000).

Los últimos papas no han sido diligentes en desvelar y condenar los numerosos casos de pederastia, en aclarar y defender de una forma contundente la verdad. Por otra parte, la alianza del poder político y religioso en la práctica de la corrupción se ejemplificaron claramente en las actuaciones de Licio Gelli, gran maestre de la logia masónica P2 (Propaganda Due) y Roberto Calvi, en combinación con el representante del Vaticano y titular del Banco Ambrosiano, monseñor Paul Marcinkus, la mafia, los medios de la extrema derecha, y la intervención una vez más de los Estados Unidos en los asuntos internacionales a través de la Red Gladio.

Estos poderes están también amenazados por los grupos especializados en el ejercicio del terror. Estos grupos terroristas, según Trump, son menos peligrosos que la extrema izquierda estadounidenses, que se manifiesta contra los asesinatos de Estado, una comparación que ya había aplicado uno de sus máximos colaboradores, para dirigirse no a los manifestantes norteamericanos, sino al partido comunista chino. Los ciudadanos experimentamos más que nuca nuestra fragilidad y vulnerabilidad y que solo somos dueños de un futuro incierto. En el plano económico la inseguridad provoca el miedo de los mercados y los fallos sistémicos favorecen siempre a la derecha (Sanahuja, 2017).

No ha desaparecido la memoria del holocausto nuclear de 1945 y se empiezan a renovar y a actualizar los equipos atómicos, como lo pone de manifiesto el hecho de que Trump y Putin empiecen a negociar el futuro del acuerdo para el control de armas nucleares. En la actualidad Estados Unidos y Rusia siguen ocupando los primeros puestos en los depósitos de armas de este tipo, seguidos a distancia por China, Francia y el Reino Unido. Vuelven a medirse las fuerzas.

En los tiempos de la posverdad y de la mentira encuentran verificación empírica las palabras de Jean Delumeau e Yves Lequin (1987), según las cuales "en la historia de las colectividades, los miedos cambian, pero el miedo persiste". Se incrementa el miedo por la amenaza de la pérdida de la biodiversidad. el saqueo ecológico de la Tierra y la monocultura, fenómeno advertido ya por Lévi-Strauss. Manuel Castells (2000) ha analizado esta situación desde los ámbitos culturales y políticos y también desde los económicos y tecnológicos, la ecología y el medio ambiente. 
Para superar esta difícil situación, se ha propuesto el concepto de multiculturalismo, que constituye, para algunos autores, una defensa contra el eurocentrismo y el colonialismo norteamericano, desde la perspectiva de la deseada desaparición de las desigualdades.

Si, según la tesis de Shohat-Stam (2002), Europa ha impuesto secularmente su discurso cultural, ellos plantean abordar los problemas y resolverlos desde un ámbito más amplio, que comprenda el resto de los continentes, sin excluir, por supuesto, a los países del denominado "tercer mundo". Además, intentan "establecer conexiones interdisciplinarias, forjando vínculos entre campos habitualmente compartimentalizados, como la teoría literaria, el cine, el periodismo, la etnografía reflexiva y experimental..." (Shohat-Stam, 2002),

En el universo de la "economía mundial" (Requeijo, 2012), el miedo a la uniformidad cultural se vence favoreciendo prácticas que desarrollen la diversidad, el hibridismo y el mestizaje. La diversidad y la propia identidad no implican en este caso separación sino alianza. Si los medios de comunicación pueden crear espectadores solitarios y consumidores fragmentados, también pueden favorecer filiaciones alternativas y de comunidad, y promover coaliciones multiculturales.

Junto al miedo a la uniformidad cultural se ha señalado por algunos sectores el del crack del sistema monetario internacional, el riesgo informático, y otros terrores más carnalmente devastadores, como el de las "plagas silenciosas", el caso de la sangre contaminada, el amianto, el de las infecciones nosocomiales tan preocupantes en estos días por las largas estancias en los hospitales, la dioxina emitida por las incineradoras de las basuras domésticas, sin olvidar las pandemias como el sida o el covid-19- auténtico azote planetario-, el terrorismo, el hambre y las guerras interminables. Si la crisis financiera no ha llegado al crack del sistema monetario internacional, los peligros no han desaparecido. Al menos así nos lo transmiten los poderes públicos a través de medios, mientras a la vez insuflan capitales millonarios a las grandes entidades financieras.

El miedo a las supuestas armas nucleares motivó, según el trío de las Azores, la guerra de Irak, y el miedo al islamismo integrista sirvió de excusa para que los gobiernos occidentales no apoyasen las revueltas de los países árabes, mientras a la vez seguía y sigue boyante la industria armamentista. La administración española, por ejemplo, en el primer semestre del año 2019 realizó un gran negocio económico con la exportación de material de defensa a Arabia Saudí, todo destinado al uso de sus Fuerzas Armadas, según ha publicado por Europa Press. A ello hay que sumar, durante ese periodo, la venta de material de defensa a Emiratos Árabes Unidos, valorado en 94.116 .000 millones por aeronaves, municiones y equipos electrónicos. Cuando los medios critican la política de 
opacidad de estas operaciones, se argumenta que es por motivos de seguridad (Font, Melero, 2020).

Además de las exportadas a otros países, la venta de armas en Estados Unidos ha alcanzado un récord en los últimos meses, coincidiendo con la crisis del coronavirus, superando anteriores registros que coincidían con masacres y tiroteos de gran repercusión. La Asociación Nacional del Rifle, el lobby más poderoso en defensa de las armas en Estados Unidos, comenta a través de Twiter que "Ios americanos acuden en masa a las tiendas de armas porque saben que la única autodefensa en la que confiar durante una crisis son las armas".

El dirigismo imperialista de los Estados Unidos alienta la compra de armas para frenar el miedo de los ciudadanos, a la vez que lo alimenta recurriendo a los nuevos medios de comunicación y a la difusión noticias falsas. El uso de algoritmos artificiales de machine learning y de redes de verificación de datos no logran terminar con las fake news. El móvil, que en el año 2019 superó por primera vez al consumo de televisión en Estados Unidos se ha convertido en el soporte de las stories, piezas audiovisuales de contenido rápido y de carácter efímero que comenzaron en Snapchat y se popularizaron a través de Instagram. Constituyen, así uno de los formatos de máximo éxito y de mayor proyección futura. A la vez, la evolución de los datos durante los últimos años pone de manifiesto que los podcast serán la clave. Estas herramientas, con un enorme valor positivo, también pueden ser utilizadas para manipular, controlar y atemorizar. Tristan Harris, extrabajador de Google y ahora director del Center for human technology, reconoce que las tecnológicas trabajan para secuestrar nuestras mentes. Por lo que respecta al ámbito español, y en cuanto al uso perverso que puede hacerse de los medios, y en concreto del móvil se han manifestado algunas instituciones oficiales, y organismos y gobiernos de comunidades autónomas. Por ejemplo, el Institut Balear de la Dona y el Govern Balear han lanzado una campaña en las redes para llamar la atención de los más jóvenes sobre la manipulación y la imposición del miedo a través del móvil. El Govern Balear solicita de forma imperativa que se "bloquee el machismo en el móvil".

Este miedo viene alimentándolo Trump en todos los medios y en todos sus discursos, como el de 3 de junio en el monte Rushmore, escenario grabado en la cultura popular, pero con una historia repleta de miedo y de terror. Para construirlo, el Gobierno estadounidense arrebató esas tierras a la tribu sioux, cuya soberanía sobre ellas le estaba reconocida desde un tratado de 1868. Las esculturas representan a los padres de la patria para el estadounidense medio, pero también un pasado que a muchos descendientes de los marginados no les gusta celebrar. Los presidentes George Washington y Thomas 
Jefferson fueron propietarios de esclavos. Abraham Lincoln abolió esa aberración, pero también ordenó la ejecución de 38 indios sioux y Theodore Roosevelt llegó a proclamar: "No voy a ir tan lejos como para decir que los únicos indios buenos son los indios muertos, pero nueve de cada 10 lo son, y no debería investigar demasiado sobre el décimo". Con la misma contundencia Donald Trump afirmó en su discurso: "Diremos la verdad tal como es, sin disculparnos: Estados Unidos de América es el país más justo y excepcional que haya existido en la Tierra".

Coincidiendo con estas declaraciones, la ONU ha realizado un llamamiento al alto el fuego mundial por la pandemia y ha declarado que la mejor moneda que pueden utilizar los Estados es la colaboración y la confianza entre ellos. Pero Trump, sin atender a las instituciones mundiales ni a los poderes judiciales, que son los que deben establecer lo que es justo o injusto, ha reiterado que él está en posesión de la justicia y de la verdad. Tal vez alguno de sus numerosos consejeros debería aconsejarle el respeto a los tratados internacionales y la lectura de las páginas escritas por los grandes pensadores sobre la verdad.

\section{Bibliografía}

Albrow, M. (1996). The Global Age. Cambridge: Polity Press

Albrow, M., M., Eade, J., Dürrschmidt, J., \& Washboourne, N. (1997). El impacto de la globalización en los conceptos sociológicos: comunidad, cultura y medio ambiente. En Eade, J. (1997). Living the Global City. Globalization as Local Process. London: Routledge, 20-36.

Alonso, J.R.\& Alonso Esquisábel, I. (2018). El alma de la neurocienica. Breve historia del conocimiento sobre el cerebro. Barcelona: Emse Edapp.

Barañano Cid, M. (1999). Postmodernismo, modernidad y articulación espaciotemporal global: algunos apuntes. En Ramos Torres, R. \& García Segas, F. eds. (1999). Globalización, riesgo, reflexividad (pp.105-135). Madrid: Centro de Investigaciones Sociológicas.

Barber, B. (2004). El imperio del miedo, guerra, terrorismo y democracia. Barcelona: Paidós Ibérica, S. A.

Bauman, Z. (2003). La globalización. Consecuencias humanas. México: FCE. 
Beck, U. (1998). ¿Qué es la globalización? Barcelona: Paidós.

Borja J. \& Castells, M. (1997). Local y global. Madrid: Taurus.

Boron, A. (2002). Imperio e Imperialismo. Buenos Aires: Consejo Latinoamericano de Ciencias Sociales.

Brzezinski, Z. (2005). El dilema de EE.UU: ¿Dominación global o liderazgo global? Barcelona: Paidós.

Carlston, K. S. (1966). Law and Organization in Word Society. Chicago: University of Illinois Press.

Castells, M. (1997). La sociedad red, volumen 1. La era de la información. Economía, sociedad y cultura. Madrid: Alianza Editorial.

--- (1998). Entender nuestro mundo, Revista de Occidente, 205, 113-145.

(2000). Globalización, Estado y sociedad civil: el nuevo contexto histórico de los derechos humanos, Isegoría. Revista de Filosofía Moral y Política, 22, 5-18.

--- (2009). Comunicación y poder. Madrid: Alianza Editorial.

Cervantes, M. de (2004). Don Quijote de la Mancha $(1605,1615)$, edición y notas de Francisco Rico. Madrid: Real Academia Española.

Cornwell, J. (2000). El Papa de Hitler. La verdadera historia de Pío XII. Barcelona: Editorial Planeta.

Chomsky, N.A. (2010). Estados fallidos. Barcelona: Público.

Del Arenal, C. (2010). Introducción a las relaciones internacionales. Madrid: Tecnos.

Dellumeau, J. \& Lequin, Y. (dirs.) (1987). Les Malheurs des temps. Paris: Larousse.

Departamento de Defensa, Nuclear Posture Review, 2018, Washington: Department of Defense 2018. 
Featherstone, M., Lash, S. \& Roberston, R. (1995). Global Modernities. London: Sage.

Fernández, J.C. (2010). Sistema de Derecho Económico Internacional. Navarra: Aranzadi.

Font, T. \& Melero, E. (2020). Armas, negocio, política, opacidad. Barcelona: Icaria.

Foucault, M. (1986). De otros espacios, Diacritics, 16, 22-27.

García Blanco, J. M. (1999). De la mundialización y la globalización al sistema de la sociedad mundial. En Ramos Torres, R. \& García Segas, F. eds. (1999). Globalización, riesgo, reflexividad (pp. 21-55). Madrid: Centro de Investigaciones Sociológicas.

García Canclini, N. (1999). La Globalización Imaginada. México: Paidós.

Giddens, A. (1993). Consecuencias de la modernidad. Madrid: Alianza Editorial.

--- (1998). The third Way. The Renewal of Social Democracy. Cambridge: Polity Press.

(2020). Hablar con extraños. Madrid: Taurus.

Hannerz, U. (1996). Transnational Connections. London: Routledge.

Harvey, D. (2007). El nuevo imperialismo. Madrid: Akal.

Heidegger, M. (1993). El ser y el tiempo (Sein und Zeit, 1927), trad. José Gaos. México: Fondo de Cultura Económica.

Herman, E. \& Mc McChesney, R. (1999). Los medios globales. Los nuevos misioneros del capitalismo corporativo. Madrid: Cátedra.

Hobbes, Th. (1966), The English Works of Thomas Hobbes, edited by Sir William Molesworth. Bart: London, Vol. I, II, III, IV.

--- (1983). Leviatán (Leviathan,1651), trad. Antonio Escotado. Madrid: Editora Nacional.

Huisman, D. (1997). Diccionario de las mil obras claves del pensamiento. Madrid: Tecnos. 
Ignatieff, M. (1986). The Needs of Strangers. London: Penguin Books.

Jameson, F. (1996). Teoría de la postmodernidad. Madrid: Trotta.

Kierkegard, S. (1984). El concepto de la angustia (Om Begrepet Angest,1844), trad. D. Rivero. Barcelona: Orbis.

Klein, N. (2001). No Logo. El poder de las marcas. Barcelona: Paidós.

Ledoux, J. (1999). El cerebro emocional. Barcelona: Ariel-Planeta.

Locke, J. (1994). Tratados del gobierno civil (Two Treatises of Gobernement, 1690). trad. C. Mellizo). Madrid: Alianza.

Luhmann, N. (1992). Beobachtungen der Moderne. Opladen: Westdeutscher.

--- (1995). Kultur als historiches Begriff, Gesellschaftsstruktur und Semantik, 4, 31-54.

(1998). Complejidad y modernidad, o de la unidad a la diferencia. Madrid: Trotta.

Maquiavelo, N. (1988). Del arte de la guerra (De re militari, 1521), trad. M. Carrera. Madrid: Tecnos.

--- (1988). El Príncipe (II pincipe, 1532), trad. H. Puigdoménech. Madrid: Tecnos.

Mannetti, G. (1995). Los modelos comunicativos y la relación texto-lector en la semiótica interpretativa. En Grandi, R. Texto y contexto en los medios de comunicación (pp.79-85). Barcelona: Bosh.

Mattelart, A. (1993). La comunicación-mundo. Madrid: Fundesco.

--- (2002). En Ramonet, I. (2002). La post-televisión. Multimedia, Internet y globalización económica (pp. 7-16). Barcelona: Icaria.

Milanovic, B. (2016). Global inequality: A New approach for the Age of Globalization, Cambridge: Harvard University Press. 
Moore, W. E. (1966). Global Sociology: The Word as a Singular System, American Journal of Sociology, 71, 457-482.

Palomares, G. (2006). Relaciones internacionales en el siglo XXI. Madrid: Tecnos.

Pellicer, M. (2017). La Comunicación en la era Trump. Barcelona: Editorial UOC.

Pérez-Agote Poveda, A. (1999). Globalización, crisis de Estado y anomía. La teoría social visita Europa. En Ramos Torre, R. y García Segas, F. eds. (1999). Globalización, riesgo, reflexividad (pp. 57-72). Madrid: Centro de Investigaciones Sociológicas.

Pieterse, J. N. (1995). La globalización como hibridación. En Featherstone, M., Lash, S. \& Roberston, R. (pp. 45-68). Global Modernities. London: Sage.

Ramonet, I. (ed.) (2002). La post-televisión. Multimedia, Internet y globalización económica. Barcelona: Icaria.

-.-- (2002). Guerras del siglo XXI (trad. José Antonio Soriano). Barcelona: Mondadori.

Ramos Torre \& García Selgas, F. (1999) eds. Globalización, riesgo, reflexividad. Madrid: Centro de Investigaciones Sociológicas.

Requeijo, J. (2012). Economía Mundial. Madrid: McGraw Hill.

Roberstson, R. (1992). Globalization: Social Theory and Global Culture. London: Sage.

Robinson, W. (2007). Una teoría sobre el capitalismo global. Bogotá: Ediciones desde abajo.

Rodrik, D. (2011). La paradoja de la globalización. Democracia y el futuro de la economía mundial. Barcelona: Antoni Bosch, 2011.

Rosales, 0. (2009). La globalización y los nuevos escenarios del comercio internacional. Cepal Review, 97, 77.

Rousseau, J.J. (1979). Discurso sobre el origen y los fundamentos de la desigualdad entre los hombres, (Discours sur l'origine et le fondements de l'inégalité parmi les hommes,1755), trad. Mauro Armiño. Madrid: Akal. 
Sanahuja, J.A. (2017). Posglobalización y ascenso de la extrema derecha: crisis de hegemonía y riesgos sistémicos, Anuario Ceipaz 2016-2017. Seguridad internacional y democracia: guerras, militarización y fronteras, pp. 41-77.

Santororo, C. (1939). La Alemania de Hitler vista por un extranjero. Berlín: Internationaler Verlag.

Schiller, H. I. (2002). El ciberespacio. Nueva arma del imperialismo. En Ramonet, I. (ed.). La post-televisión. Multimedia, Internet y globalización económica (pp. 117132) Barcelona: Icaria.

Sohat, E. \& Stam, R. (2002). Multiculturalismo, cine y medios de comunicación. Barcelona; Paidós.

Stiglitz, J. E. (2007). El malestar en la globalización. Madrid: Punto de Lectura.

Störig, H. J. (1997). Historia universal de la Filosofía. Madrid: Tecnos.

Tzu, S. (1999). El arte de la guerra. Barcelona: Editorial Martínez Roca.

Vallespín, F. (2012). La mentira os hará libres. Realidad y ficción en la democracia. Barcelona: Galaxia Gutenberg/ Círculo de Lectores.

Villanueva, D. (2019). Corrección política, lengua y posverdad. Madrid: Fundación Santillana.

Virilio, P. (2002). Videovigilancia y delación generalizada. En Ramonet I. (ed.) (2002). La post-televisión. Multimedia, Internet y globalización económica (pp.7380). Barcelona: Icaria.

Wolf, M. (1997). Las influencias discretas, CIC, Servicio de Publicaciones UCM, 3, 243-256.

Wolton, D. (1991). Las contradicciones del espacio público mediatizado, Hermes, 10, 13-22. 
